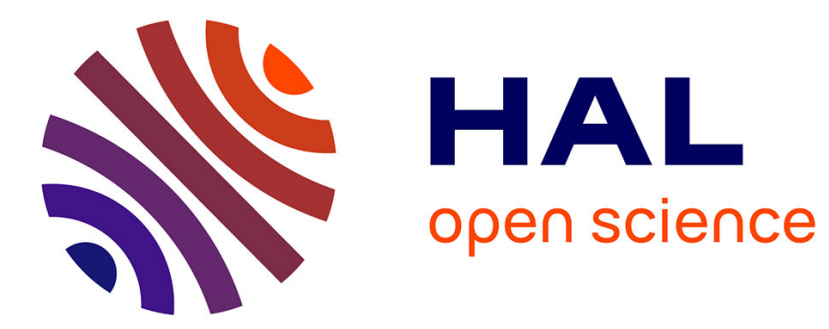

\title{
Product-Service Systems Delivered by SMEs During Building Use Stage: Sustainability Criteria Framework \\ Davide Gamba, Elena Malakhatka
}

\section{To cite this version:}

Davide Gamba, Elena Malakhatka. Product-Service Systems Delivered by SMEs During Building Use Stage: Sustainability Criteria Framework. 22nd Working Conference on Virtual Enterprises (PRO-VE 2021), Nov 2021, Saint-Etienne, France. pp.65-80, 10.1007/978-3-030-85969-5_6 . emse-03327337

\section{HAL Id: emse-03327337 https://hal-emse.ccsd.cnrs.fr/emse-03327337}

Submitted on 24 Nov 2021

HAL is a multi-disciplinary open access archive for the deposit and dissemination of scientific research documents, whether they are published or not. The documents may come from teaching and research institutions in France or abroad, or from public or private research centers.
L'archive ouverte pluridisciplinaire HAL, est destinée au dépôt et à la diffusion de documents scientifiques de niveau recherche, publiés ou non, émanant des établissements d'enseignement et de recherche français ou étrangers, des laboratoires publics ou privés. 
Gamba D., Malakhatka E. (2021) Product-Service Systems Delivered by SMEs During

Building Use Stage: Sustainability Criteria Framework. In: Camarinha-Matos L.M.,

Boucher X., Afsarmanesh H. (eds) Smart and Sustainable Collaborative Networks 4.0.

PRO-VE 2021. IFIP Advances in Information and Communication Technology, vol 629.

Springer, Cham. https://doi.org/10.1007/978-3-030-85969-5_6

\title{
Product-Service Systems Delivered by SMEs During Building Use Stage: Sustainability Criteria Framework
}

\author{
Davide Gamba ${ }^{1}$ and Elena Malakhatka ${ }^{2}$ \\ ${ }^{1}$ University of Bergamo, Department of Management, Information and Production \\ Engineering, Italy \\ davide.gamba@unibg.it \\ ${ }^{2}$ KTH Royal Institute of Technology, Sweden \\ elenama@kth.se
}

\begin{abstract}
The building use stage offers the opportunity to provide valuable and sustainable product-service systems (PSS) that enhance the buildings' value for the end-users. Many of them are delivered by networks of stakeholders that actively involve small and medium enterprises (SMEs). We have combined an existing literature review with the multiple stakeholders' feedback to identify several problems and define the main hypothesis: diverse and presented in a structural way information about PSS can contribute to a better understanding of the added value by multiple stakeholders. We have co-created a list of criteria, which were formed into the sustainability multi-criteria framework. The proposed framework also supplements PSS-specific criteria, such as PSS type, PSS collaborative partnership networks type, and PSS integration type. A list of findings related to the topic was declared to help further develop the study, such as the correlations between PSS-related and PSS sustainability-oriented criteria.
\end{abstract}

Keywords: product-service system (PSS); SMEs; collaborative partnership networks; sustainability criteria; building use stage

\section{Introduction}

Achieving sustainable competitive advantage based upon product-service systems (PSS) provision is often claimed to be viable for businesses. There has, however, been little evidence captured on the application of aspects of servitization in general and developing well-functioning integrated solutions within real estate development in particular [1]. Integrated solutions refer to the PSS concept, as they are defined as bundles of physical products, services, and information, seamlessly combined to provide more value than the parts alone, that address customer's needs concerning a specific function or task in their business system [2]. However, PSS seems far to be methodically applied by real-estate industry's firms, especially small and medium enterprises (SMEs). SMEs represent $99 \%$ of all non-financial businesses in the EU, providing two-thirds of the total private sector employment [3].

Literature has primarily concentrated efforts on large companies [4] even though servitization occurs in all types of supply chains, including the ones that involve SMEs. 
Literature has devoted few efforts about servitized collaborative partnerships that involve SMEs [5, 6], concentrating on the manufacturing industry and neglecting the real estate. This highlights a clear research gap. On the other hand, collaborative partnerships with and between SMEs represent a strategic opportunity even for buildings owners that can enhance the value of their assets during the operating use phase. In fact, recent research [7] involving 340 international companies shows that partnerships with SMEs are expected to impact their total revenues by up to $19 \%$ in the three years following the start of the collaboration. While there are numerous collaborative partnerships and alliances in the real estate sector between established players, many industry experts highlight a need to include SMEs in their business ecosystems.

In this paper, we primarily focus on the use stage of the building - which is also named as operation stage in many professional literatures - emphasizing on end-users related PSS. Grounded on all the above, we concluded that the topic of PSS delivered by SMEs through collaborative partnership to the building use stage is relevant and requires profound and comprehensive research. This study is the first step towards understanding this complex and interdisciplinary field developing a framework that attempts to bridge through a sustainable perspective SMEs' PSS collaborative partnerships networks implemented to deliver value to stakeholders with the real one perceived from the latter. We identified gaps from the overlap of literatures about real estate and building use stage, PSS business model innovation, and role of SMEs in the business ecosystem. Hence, based on the available general knowledge about PSS and qualitative data from the interviews with actors representing building industry, SMEs, and end customers, we developed the main hypothesis: more structured and diverse information about PSS can help to assess its potential and contribute to the more sustainable implementation of PSS delivered by SMEs for the building use stage. Built on the multi-actors' feedbacks, we have created a list of criteria, which were identified as necessary to a better understanding of the added value of the PSS. These criteria were compared and supplemented by the criteria already existing in academic practice and formed into the sustainability multi-criteria framework. The proposed framework also supplements PSS-specific criteria, such as PSS type, PSS partnership type and PSS integration type. This study is explorative and has some limitations, which are listed in the final part.

\section{Research Methodology}

This research's design follows the schema traced in Fig.1. The first stage is the observation phase: the research object is interpreted, while gaps and research questions are detected. In addition, we have added the experts' feedback to align the process with market knowledge. We identified the problem during the second phase, based on the existing literature review and experts' feedback collected. Last, the third phase - namely theory building and tool development - was carried out to create a tool for evaluating added value of PSS from the point of three dimensions of sustainability and general PSS characteristics. 


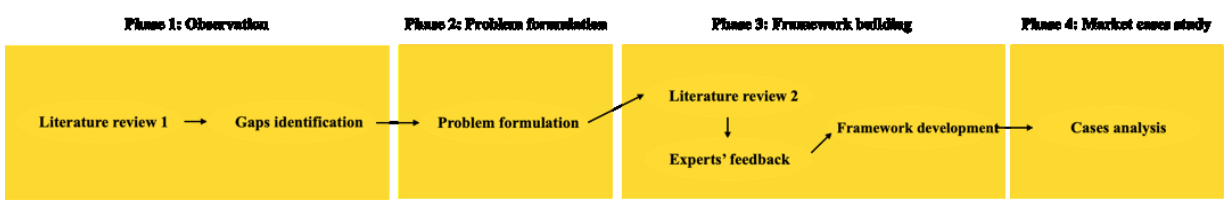

Fig. 1. Research design and methodology.

The experts' feedback is based on a mixed-method approach [8], that combines semi-structured expert interviews and quantitative survey. We interviewed KTH Livein-Lab's 12 key actors in in real estate innovation arena from Sweden, Germany, and France ${ }^{1}$. The key issues in the interviews were an evaluation of general relationship with PSS business model and different sustainability dimensions. Their potential and actual courses of action and strategies towards using more PSS. We analysed the interviews by applying a category system derived from network theory and frame analysis [21] to identify the members of the network and their respective priorities for use of PSS in the buildings. The list of experts and their roles are presented in Table 1.

Table 1. Participants of the feedback sessions.

\begin{tabular}{|c|c|c|}
\hline Actor category & Role & Background \\
\hline Property related & $\begin{array}{l}\text { Director } \\
\text { Property manager } \\
\text { Chief of Innovation } \\
\text { Facility manager } \\
\text { Main architect } \\
\text { Project manager } \\
\text { Head of Smart Home } \\
\text { Innovation manager }\end{array}$ & $\begin{array}{l}\text { Large Scandinavian property development firm } \\
\text { Large Scandinavian property development firm } \\
\text { Large Scandinavian property development firm } \\
\text { Building IT firm } \\
\text { Large European architecture bureau } \\
\text { Large European architecture bureau } \\
\text { Furniture producer } \\
\text { Home appliances firm }\end{array}$ \\
\hline$S M E$ & $\begin{array}{l}\text { CEO } \\
\text { CTO } \\
\text { Founder } \\
\text { IT Chief }\end{array}$ & $\begin{array}{l}\text { Last meter services } \\
\text { Smart water metering } \\
\text { Home energy management } \\
\text { Smart thermostats }\end{array}$ \\
\hline End-user & $\begin{array}{l}\text { Tenant at student apartment } \\
\text { Tenant of newly built property } \\
\text { Tenant of retrofit }\end{array}$ & $\begin{array}{l}\text { Age group 20-25 } \\
\text { Age group 35-50 } \\
\text { Age group 55+ }\end{array}$ \\
\hline
\end{tabular}

\section{Theoretical Boundaries and Literature Highlights}

The property development process is driven by the interrelationships among actors and therefore requires an institutional research approach, which is supported by qualitative analysis [9]. A further institutional approach know as structures of provision was

\footnotetext{
${ }^{1}$ See www.liveinlab.kth.se
} 
developed by $[10,11,12]$, suggesting that the production and consumption (i.e., provision) of buildings is a physical and social process guided by economic interests [13].

In this study our focus will be on the building use stage (i.e., provision), as we see that this stage is the least regulated and most dynamic in terms of innovation and relevance from several points of view. First, during the use of the building, we directly deal with the use of different kinds of resources, which creates an opportunity to influence various consumers' choices and create a prerequisite for changing the building use in a more environmentally sustainable manner. Secondly, during the building use stage, we touch on the topic of everyday life of the end-users and their wellbeing and health, which can bring us the opportunity to increase overall social sustainability and can contribute to the more sustainable future of the whole society. Thirdly, the use stage of the building has the highest potential for implementing smart home solutions, more of which are PSS. The latter indicates "marketable systems of products and services capable of fulfilling a user's demand" [14] and a strong relationship with users enhances the market competitiveness of a company. Smart home scenarios [15] suggests that service elements are important for fulfilling user needs and offering values. As developing the high technology for smart home providing various services are realized through partnership, synergies among stakeholders from diverse areas are required. In this context, PSS development methodology can encourage cooperation among various stakeholders. Constructing multi-dimensional collaborative partnership allows stakeholders to take advantage of professional knowledge, advanced technology and high-quality products or services of other companies and lower system costs at the same time [16]. PSS development tools or methods to analyze stakeholders' needs and to help their communication and involvement can contribute to PSS development involving a variety of stakeholders.

It is a matter of fact that transition towards smarter home and more PSS applications requires not only new design methodologies of the buildings and products that support our everyday life, but also need to redesign business models towards through circular and pro-environmental approaches. That is why the next theoretical pillar in PSS is a new approach for an environmentally oriented business model.

This study is interdisciplinary and lies at the junction of three different fields: real estate (building use stage), business model innovation (PSS model), and business ecosystem (collaborative partnership networks with and between SMEs). At the initial stage of the study, it is important to prioritize which sub-divisions in the selected areas may have practical knowledge. Based on the initial research of these fields, we decided to create some theoretical boundaries within each major field. Considering the overall complexity of the context (i.e., real estate business), we need to expand the business ecosystem and bring new players into the game. SMEs demonstrated the ability to quickly respond to different challenges and deliver value to the end-users through collaborative networks, which makes us focus on them in this study. We will delve deeper into each of these areas in the next chapter. 


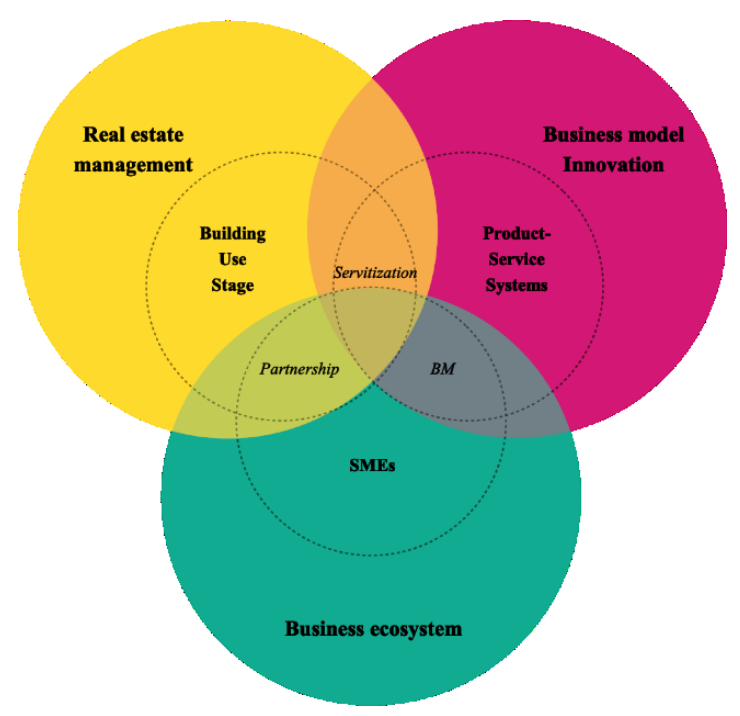

Fig. 2. Research's theoretical boundaries.

\section{Problem Formulation}

Based on theoretical gaps highlighted in the previous chapter from the literature review and the first experts' feedback sessions, Table 2 identified a few systematic problems related to the PSS delivery to the end-user of the building by SMEs and the related domain.

Table 2. Identified problem summary by multiple actors.

\begin{tabular}{|c|c|c|}
\hline Identified problems & Problem domain & Problem owner \\
\hline Lack of PSS integration mechanisms for SMEs & ICT Infrastructure & Property owner, SME \\
\hline Lack of understanding of PSS delivery mechanism & Tool and methods & Property owner, SME \\
\hline Lack of understanding of PSS added value & Knowledge & $\begin{array}{l}\text { Property owner, SME, } \\
\text { end-user }\end{array}$ \\
\hline
\end{tabular}

All three problems are significant and deserve to be researched, but due to the specific focus on the end-user perspective, we will focus on the third one (i.e., lack of understanding of general PSS added value). Following the problem formulation, we have designed a working research question for this explorative study: Which criteria explain PSS added value in the best possible way to each actor?

In addition, we have added two sub questions:

SRQ1: Which information about PSS would be relevant for each actor?

SRQ2: Which sustainability-oriented criteria could be relevant for each actor? 


\section{PSS Multi-criteria Framework Development}

A comprehensive literature review on the topic of sustainability and value assessment in PSS development was done by [17, 18, 19]. In [17] authors distinguish five aspects - clustered in two groups - that need to be considered when evaluating a PSS:

- Provider oriented: economic, environmental, societal.

- Customer oriented: acceptance, satisfaction.

In this study, we decided to include customers' related criteria into social sustainability as an individual level representation of social sustainability, even if we clearly understand that customers' related criteria relate to economic sustainability as well.

To align the general theories about PSS sustainability assessment with the context of the built environment, we have interviewed multiple actors: building owners, SMEs delivering PSS to the existing buildings, and residents of several buildings. Based on the literature analysis, we compiled a list of 18 criteria (six criteria for each sustainability dimension). Then, we provided this list in the form of a survey (google form) to our experts to prioritize the criteria. Different actors gave preference to different criteria according to their needs. Table 3 shows a generalized summary of criteria from different actors' perspectives and correlation of each criteria with sustainability dimension is shown.

Table 3. PSS sustainability criteria identified by multiple actors.

\begin{tabular}{lll}
\hline Actor & Prioritized criteria & Sustainability dimensions \\
\hline \multirow{2}{*}{ Property owner } & Cost optimisation & Economic \\
& Resource consumption & Environmental \\
& Innovation & Economic \\
SME & Market size & Economic \\
& ROI & Economic \\
& Customer satisfaction & Societal (individual level) \\
\multirow{2}{*}{ End-user } & Price category & Economic \\
& Overall experience & Societal (individual level) \\
& Environmental impact & Environmental \\
\hline
\end{tabular}

Based on this knowledge, we have created an overall PSS sustainability multicriteria framework, which can help to pre-evaluate different PSS cases and understand how well they are addressing their added values from different sustainability perspectives.

Environmental dimension of sustainability is represented by resource efficiency criteria, eco materials criteria and circularity criteria. Economical sustainability is represented by market size criteria, cost optimisation criteria and ROI criteria. Social sustainability is represented by social wellbeing (societal level), needs fulfilment and overall experience (individual level). Due to the nature of the overall assessment and multivariate data for each criterion we have decided to use a radar chart as a method for comprehensive evaluation. 
Because this exploratory study is addressed to the early decision-making stage, we propose to carry out an assessment using a scale-based assessment method using three main categories: low, medium, and high scores. Thus, we have a simplified system for evaluating each criterion without having a large number of different types of data. Of course, this approach is generalized and requires a subsequent more detailed qualitative assessment as the next step. But at this stage, this approach is sufficient to have grounds for further, more in-depth study of both the criteria themselves and the reasons why specific criteria have a particular value.

Table 4. PSS sustainability multi criteria assessment guidance.

\begin{tabular}{|c|c|c|c|c|c|c|c|c|c|}
\hline \multirow[t]{2}{*}{ Soare } & \multicolumn{3}{|c|}{ Femente } & \multicolumn{3}{|c|}{ Soctel } & \multicolumn{3}{|c|}{ Intrangen } \\
\hline & 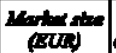 & Cost & ROI & 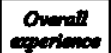 & 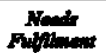 & Socked & 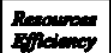 & Exom & Cinculantsy \\
\hline Low: $1-2$ & $<100000$ & $\begin{array}{l}\text { Not part of } \\
\text { vilug prop. }\end{array}$ & $<3$ & & - & $\begin{array}{l}\text { Net pecte of } \\
\text { vilio prepp. }\end{array}$ & Netpeter & $\begin{array}{l}\text { Not pat of } \\
\text { Nine peep. }\end{array}$ & $\begin{array}{l}\text { Noxpat of } \\
\text { ving prop. }\end{array}$ \\
\hline Medium: 3-5 & $\begin{array}{l}100000 . \\
1000000\end{array}$ & 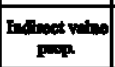 & $s=10$ & Fon & - & 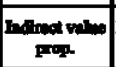 & $\begin{array}{l}\text { Indinest vilum } \\
\text { Frop. }\end{array}$ & 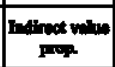 & 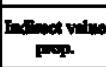 \\
\hline High: 6-8 & $>1000000$ & Dhere & $>10$ & & - & mimote & Dimport & Dinot & Dheat \\
\hline
\end{tabular}

\section{Market Cases Analysis}

To apply newly generated knowledge into practice, we decided to select several market cases and analyse them from the point of the proposed framework (Table 5). Due to the scope of this paper, the analysis was made empirically. The main selection criteria of SMEs for this case study were:

- representing different types of PSS.

- end-user oriented (B2C or B2B2C).

- EU based.

Data were collected from secondary sources.

Table 5. Market SMEs' PSS cases from building use stage (B2C / B2B2C).

\begin{tabular}{llll}
\hline Name & Brief description & $\begin{array}{l}\text { Product } \\
\text { component }\end{array}$ & Service component \\
\hline $\begin{array}{l}\text { Sangalli } \\
\text { (Italy) }\end{array}$ & $\begin{array}{l}\text { Sangalli Technologies focuses on project } \\
\text { consultancy, technical assistance and } \\
\text { maintenance for sound systems, video, } \\
\text { lighting and digital signage. }\end{array}$ & $\begin{array}{l}\text { Sound systems, } \\
\text { video, lighting and } \\
\text { digital signage }\end{array}$ & $\begin{array}{l}\text { Project consultancy, } \\
\text { technical assistance, } \\
\text { and maintenance }\end{array}$ \\
$\begin{array}{l}\text { Standard } \\
\text { Access } \\
\text { (Ireland) }\end{array}$ & $\begin{array}{l}\text { Standard Access focuses on building's } \\
\text { access management through Sonic }\end{array}$ & $\begin{array}{l}\text { Handshake, a technology that allows to } \\
\text { eliminate keys and cost associated with locks } \\
\text { changing. }\end{array}$ & $\begin{array}{l}\text { Digital platform for } \\
\text { access systems remote } \\
\text { set-up and management }\end{array}$ \\
\end{tabular}




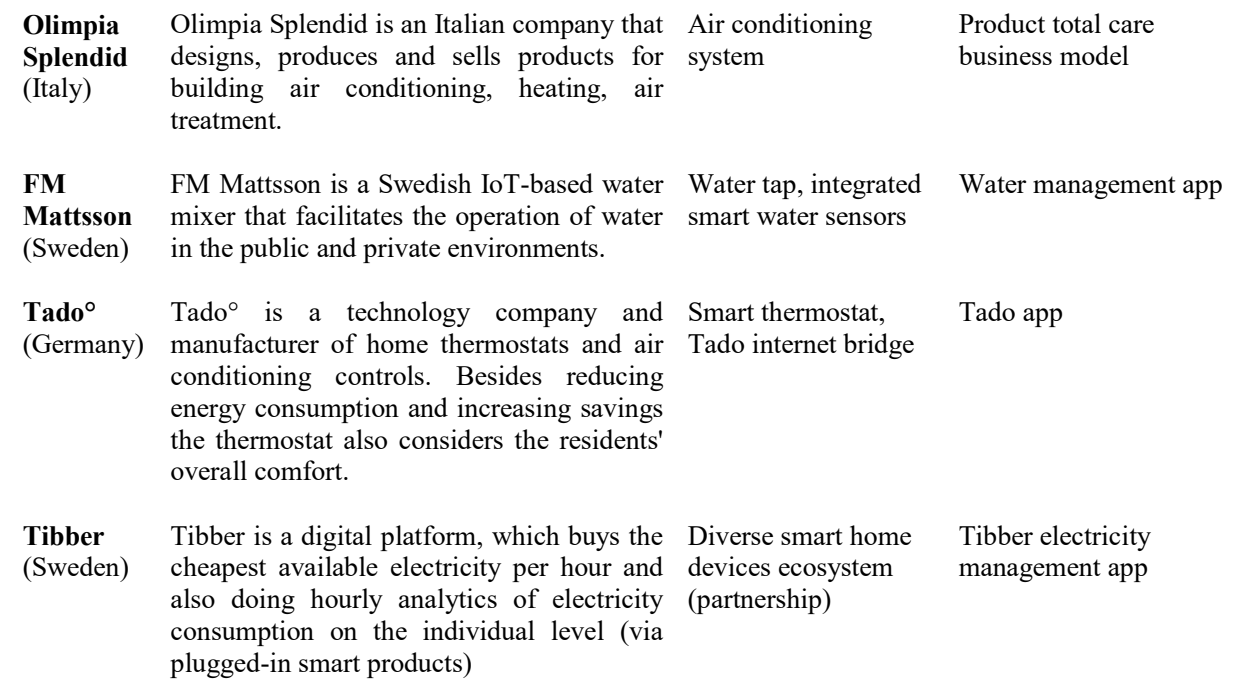

\section{$7 \quad$ Results and Discussion}

\subsection{PSS Related Criteria}

Selected market cases were associated with value constellations (i.e., collaborative partnership network) identified by [5], namely the configuration of firm's direct network relationships into distinct, specific, and integrated structures to create value. In addition, the taxonomy used [20] to cluster PSS allow to classify them among product oriented (PO) PSS, use oriented (UO) PSS, and result oriented (RO) PSS. PO PSS highlights vertical integration partnerships, while UO vertical ones. On the other hand, RO PSS mixes both horizontal and vertical integration types. Results from empirical cases analysis is shown in Table 6.

Table 6. PSS related criteria summary.

\begin{tabular}{llll}
\hline Name & PSS type & Partnership type & Service component \\
\hline Sangalli & Product-oriented (PO) & System integration & Vertical \\
Standard Access & Use-oriented (UO) & Specialist externality & Horizontal \\
Olimpia Splendid & Result-oriented (RO) & $\begin{array}{l}\text { Dual customer contact } \\
\text { partnership }\end{array}$ & Horizontal and vertical \\
FM Mattsson & Product-oriented (PO) & $\begin{array}{l}\text { Competence co-location } \\
\text { Con }\end{array}$ & Vertical
\end{tabular}


Tado $^{\circ}$

The partnership network for each PSS case is presented on the Fig. 3. Based on summary result presented in Table 6, we can find the following correlations. Productoriented PSS show mostly vertical integration of service components among involved actors, rather than use-oriented and result-oriented ones. The latter are characterized by horizontal integration forms, which explain a smaller number of partners but with more robust relationships. From the other side, the vertical integration opens opportunity for many partners to join the collaboration network in an open and easy way. One of the cases selected (i.e., Tibber) in a outlier due to its deservitization approach [22].

The next logical step is to analyse each case in a more profonde way by applying PSS sustainability multi criteria assessment framework proposed in chapter 5. It is important to analyse each case from different dimensions to reach an objective vision of each case performance. That is why we propose to examine each case from three sustainability dimensions: economic, social, and environmental.

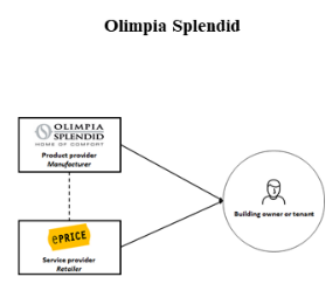

FM Mattsson

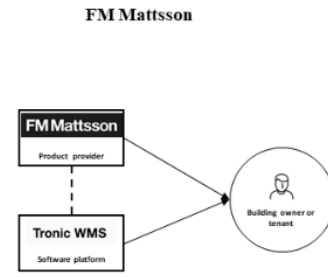

Standard Access

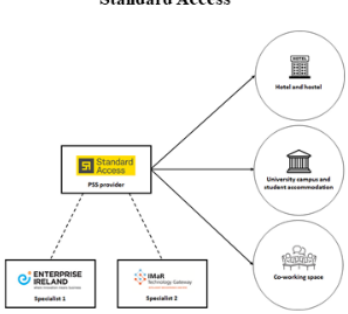

TADO

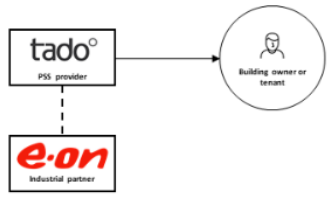

Sangalli

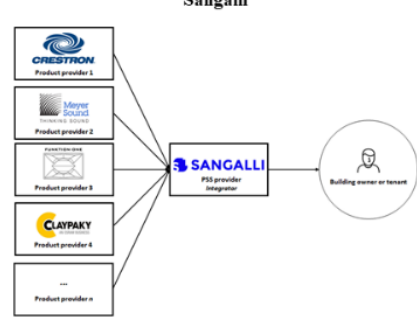

Tibber

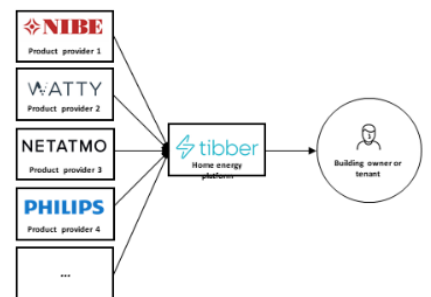

Fig. 3. Collaborative partnership network of each of six cases: Olimpia Splendid, Standard Access, Sangalli, FM Mattsson, TADO, and Tibber. 


\subsection{PSS Sustainability Related Criteria}

Based on the available data about each of six cases the proposed in chapter 5 PSS sustainability multi criteria assessment was organized. The results of the analysis are presented in the form of radar charts, which are a useful way to display multivariate observations with an arbitrary number of variables. For this stage of the study, we just assume that all criteria will be considered equally important to reflect the general view of each case study.

We clearly understand that the proposed list of PSS sustainability multi-criteria is just a first attempt to create an objective framework and have a lot of limitations and assumptions, which will be discussed in the discussion part of this report.

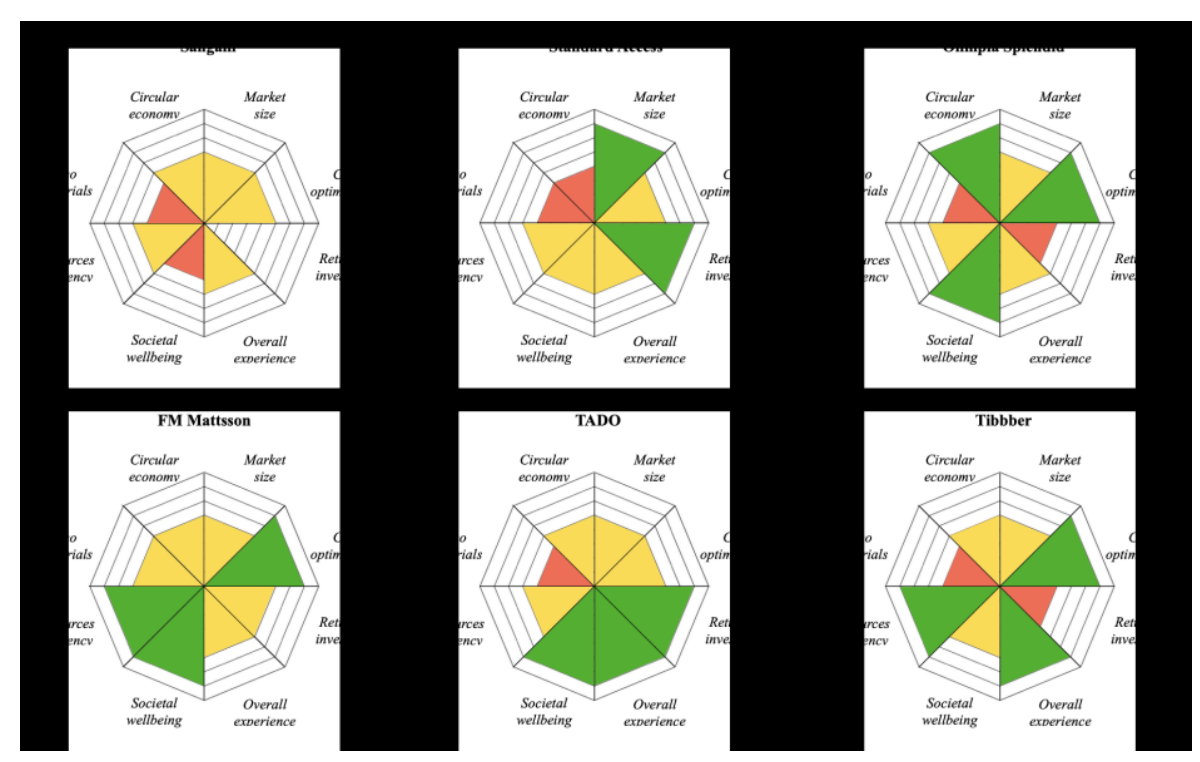

Fig. 4. PSS sustainability related criteria summary for each market cases.

\section{Conclusions}

In this section, we summarise findings, limitations, and further research opportunities of this study highlighting the role of SMEs' collaborative partnership networks.

This study explores the role of SMEs network for PSS delivery in the real estate industry's operations stage, which it has never been used to describe servitized SMEs in literature to the best of our knowledge. We have developed a framework that attempts to bridge through a sustainable perspective SMEs' PSS collaborative partnerships networks implemented to deliver value to stakeholders with the real one perceived from the latter. This framework represents a tool for practitioners - both managers and entrepreneurs from SMEs - that aims to properly design and understand the added value 
transfer to end-users. Despite multi-actors have different priorities, KTH Live-in-Lab's expert discussions and empirical cases preliminary analysis suggests correlations between PSS related criteria and sustainability-oriented criteria. For instance, selected use-oriented PSS cases are delivered through a specialist externalities collaborative partnership network, which highlights the return on investment as a critical dimension for stakeholders. Again, selected result-oriented PSS cases show that cost optimization dimension is an important value perceived by stakeholders, arising from the fact that economic sustainability is more prior for PSS SMEs then environmental sustainability, which can make us conclude that it is not an easy task to balance a high performance of both.

This paper is not exhaustive, and it presents a set of limitations. Due to the uniqueness of the field, the findings already mentioned cannot be fully generalized. In addition, the framework is based on authors' personal choices about both PSS related and sustainability criteria. In fact, literature has defined different classifications for PSS, SMEs' collaborative networks, and sustainability criteria. This means that the proposed framework represents just a point of view over added values perceived by stakeholders: an objective understanding of the argument is partially achieved by the proposed framework. The analyses relied on a small number of empirical cases based on secondary data collected, as well as a small group of experts from the KTH Live-inLab involved in the discussion that led to the identification of the sustainability criteria.

Based on findings and limitations described, this study opens a set of potential further research. First, the number of empirical cases and experts involved should be selected from different industries and increased to get more evidence regarding the correlation among the different dimensions involved into the framework and its general application. All the collaborative partnership networks identified by [5] should be analysed. Then, cases should be based both on primary and secondary data. In addition, data should be collected from all the actors involved in the collaborative network to take care of stakeholders' different interests. The application of the framework in other phases of the building's life cycle constitute a promising opportunity to validate the tool developed. Once certified, the tool will benefit from ICT contributions for facilitating and spreading data collection from stakeholders and related analysis. Another important area of research is represented by the identification of the optimal business model that allows to successfully manage both economic and environmental sustainability values along the collaborative network. In this direction, a deeper understanding of SMEs' unique sees and network mechanisms is needed.

\section{References}

1. Zighan, S., \& Bamford D.: Sustainable competitive advantage through servitization: An investigation into servitization strategy in the real estate development sector. $22^{\text {nd }}$ EurOMA Conference (2015).

2. Brax, S. A., \& Jonsson, K.: Developing integrated solution offerings for remote diagnostics: a comparative case study of two manufacturers. International Journal of Operations \& Production Management (2009).

3. European Commission - EASME: Annual Report on European SMEs (2019). 
74 D. Gamba and E. Malakhatka

4. Adrodegari, F., Saccani, N., Kowalkowski, C., \& Vilo, J.: PSS business model conceptualization and application. Production Planning \& Control (2017).

5. Kowalkowski, C., Witell, L., \& Gustafsson, A.: Any way goes: Identifying value constellations for service infusion in SMEs. Industrial Marketing Management (2013).

6. Lelah, A., Mathieux, F., Brissaud, D., \& Vincent, L.: Collaborative network with SMEs providing a backbone for urban PSS: a model and initial sustainability analysis. Production Planning \& Control (2012).

7. McHale, J.: StartUps and their Impact on Smart Buildings 2021. Memoori Research AB (2021).

8. Hollstein, B.: Mixed methods social networks research: an introduction. Mixed methods social networks research: design and applications 1 (2014).

9. Adams, D., Dunse, N., White, M.: Conceptualising state-market relations in land and property: the growth of institutionalism. Planning, public policy and property markets (2005).

10.Ball, M.: Housing policy and economic power: the political economy of owner-occupation. Methuen, London, England (1983)

11.Ball, M.: Coming to terms with owner-occupation. Capital and Class (1985).

12.Ball, M.: Housing analysis: time for a theoretical refocus. Housing Studies (1986).

13.Gore, T., and Nicholson, D.: Models of the land-development process: a critical review. Environment and Planning (1991).

14.Brezet, J. C., Bijma, A. S., Ehrenfeld, J., \& Silvester, S.: The design of eco-efficient services. Methods, tools and review of the case study based "Designing eco-efficent Services" project (2001).

15.Kim, S., \& Baek, J. S.: Diagnosis of current smart home appliance development process for application of PSS design methodology. DS 77: Proceedings of the DESIGN 2014 13th International Design Conference (2014).

16.Tukker, A., \& Tischner, U.: Product-services as a research field: past, present, and future. Reflections from a decade of research. Journal of cleaner production (2006).

17.Nakada, T., Sholihah, M. A., Mitake, Y., \& Shimomura, Y.: Toward the development of a comprehensive product-service system (PSS) evaluation method. Procedia CIRP (2020).

18.Bertoni, M., Multi-criteria decision making for sustainability and value assessment in early PSS design. Sustainability (2019).

19.Sundin, E., Nässlander, E., \& Lelah, A.: Sustainability Indicators for small and medium-sized enterprises (SMEs) in the transition to provide product-service systems (PSS). Procedia CIRP (2015).

20.Baines, T., Ziaee Bigdeli, A., Bustinza, O. F., Shi, V. G., Baldwin, J., \& Ridgway, K.: Servitization: Revisiting the state-of-the-art and research priorities. International Journal of Operations \& Production Management (2017).

21.Borgatti, S.P., \& Halgin D.S.: On network theory. Organization science (2011).

22.Kowalkowski, C., Gebauer, H., Kamp, B., \& Parry, G.: Servitization and deservitization: Overview, concepts, and definitions. Industrial Marketing Management (2017). 